\title{
COTAS DE RESERVA AMBIENTAL: UM ESTUDO POR MEIO DOS CRITÉRIOS DE AVALIAÇÃO DE POLÍTICA PÚBLICA AMBIENTAL
}

\author{
Zenaide Rodrigues Ferreira ${ }^{1}$ \\ Lucas Vitor de Carvalho Sousa ${ }^{2}$ \\ Andreia Brasil Santos ${ }^{3}$ \\ Márcio Antônio Couto Ferreira ${ }^{4}$
}

\begin{abstract}
RESUMO
O sistema regulatório ambiental brasileiro, estabelecido pelo Código Florestal, é utilizado para a conservação de florestas em propriedades agrícolas privadas. Entre vários instrumentos para gerenciar o uso da vegetação natural e outras áreas sensíveis nas explorações rurais, há uma correlação entre políticas de comando e controle e preservação. Entende-se que esse objetivo foi alcançado antes da instituição do novo Código Florestal. No entanto, é importante mencionar alguns argumentos a favor que com a institucionalização desse quadro jurídico em 2012 trouxe novas ideias. Uma dessas novidades foi a Cota de Reserva Ambiental (CRA), que permitiu a compensação de déficits em reservas legais por meio de uma negociação entre proprietários com déficits e superávits na vegetação nativa dentro de outras propriedades. Nesse contexto, o presente trabalho pretende estudar este novo instrumento instituído por lei, utilizando os critérios de avaliação de política pública ambiental. Como resultado, conclui-se que o instrumento de CRA ainda foi influenciado por variáveis externas, que incluíram alguma insegurança técnica, jurídica e administrativa. Além disso, os ganhos ambientais estão muito distantes da eficácia desse instrumento político. Os regulamentos e padrões estabelecidos aumentaram os conflitos socioeconômicos, essencialmente por uma combinação de mecanismo de recompensa e punição.
\end{abstract}

Palavras-chave: Novo Código Florestal; Política Ambiental; Cadastro Ambiental Rural; Cota de Reserva Ambiental.

\footnotetext{
${ }^{1}$ Doutoranda no Programa de Pós-Graduação em Economia na Universidade de Brasília - UnB. E-mail: zenaide.r.ferreira@gmail.com.

2 Professor Adjunto do Departamento de Economia e Análise da Universidade Federal do Amazonas - UFAM. E-mail: lucassousa@ufam.edu.br.

3 Professora Associada do Departamento de Economia e Análise da Universidade Federal do Amazonas - UFAM. E-mail: brasiland@ufam.edu.br.

${ }_{4}$ Professor Adjunto do Departamento de Economia e Análise da Universidade Federal do Amazonas - UFAM. E-mail: marciocout@yahoo.com.br
} 


\title{
ENVIRONMENTAL RESERVE QUOTAS: A STUDY THROUGH CRITERIA THE PUBLIC ENVIRONMENTAL POLICY
}

\begin{abstract}
Brazilian environmental regulatory system, established by the Forestry Code, is used for the conservation of forests in private agricultural exploitations. Amongst several instruments to manage the use of natural vegetation and other sensitive areas in rural exploitations, there is a correlation between a command and control policies and preservation. We understand that this objective was achieved before the institution of the new Forest Code. Nonetheless, it is important to mention some favor arguments. Therefore, the institutionalization of this legal framework in 2012 brought new ideas. One of these novelties was the Environmental Reserve Quota (CRA) that has allowed the compensation of deficits in legal reserves through a negotiation between deficit owners and surpluses in native vegetation within other properties. In this context, the current paper intends to study this new instrument instituted by the law, using environmental public policy evaluation criteria. As a result, we conclude that the CRA instrument has still influenced by external variables, which have included some technical, legal and administrative insecurity. Furthermore, environmental gains are far away from the effectiveness of this policy instrument. Regulations and standards established have increased socioeconomic conflicts, essentially by a combination of reward and punishment mechanism.
\end{abstract}

Key words: Forest Code; Environmental Policy; Rural Environmental Registry; Environmental Reserve Quota.

\section{INTRODUÇÃO}

Diversas são as classificações dos instrumentos de política de gestão ambiental encontradas na literatura (BAUMOL; OATES, 1979; ALMEIDA, 1998; PERMAN et al., 2003; STERNER; CORIA, 2012). A bibliografia técnica costuma classificar tais instrumentos em três grandes grupos: $i$ ) instrumentos de comando e controle ou instrumentos regulatórios; ii) instrumentos econômicos, e; iii) instrumentos voluntários ou de persuasão. Essa classificação, todavia, nem sempre é uniforme em torno dessas categorias (NOGUEIRA; PEREIRA, 2000).

No Brasil, a implementação desses instrumentos tem vias extensas e contam com políticas que envolvem licenças, taxas, subsídios, estabelecimentos de padrões, avaliação de impacto ambiental, zoneamento, acordos voluntários, entre outros. Embora o arsenal seja bastante diverso, a adoção de qualquer um desses tipos de instrumentos de política ambiental não é tarefa trivial para um 
gestor e deve, ou pelo menos, deveria levar em consideração vários critérios relacionados à escolha de políticas públicas. Alguns desses critérios são sugeridos por Perman et al. (2003), quais sejam: a eficiência, a confiabilidade, a equidade, os custos sobre incerteza, a permanência (efeitos de longo prazo), a eficiência dinâmica, a aplicabilidade, e outros. O sucesso da aplicação de determinado instrumento de política ambiental está intimamente relacionado a estes critérios de escolha que devem ser bem conhecidos e explicitados.

Atualmente, os instrumentos de política de gestão ambiental de proteção às florestas no Brasil estão no centro das principais preocupações ambientais e vem desafiando a adoção de medidas aptas a implementar o conceito de desenvolvimento sustentável. Parte do interesse na proteção florestal está relacionada ao carbono e às mudanças climáticas e outra parte relaciona-se a preocupação com a biodiversidade e demais bens e serviços ecossistêmicos (ALCANTRA, 2016; COSTA, 2016). Para que esse compromisso seja assumido é evidente a necessidade de intervenção do Estado para que terras cobertas com floresta assim permaneçam.

Nesse sentido chama atenção a legislação florestal brasileira, que historicamente cumpre o papel de principal mecanismo utilizado pelo governo orientado para a conservação de florestas em terras privadas, e é operacionalizada pelo novo Código Florestal, convertido pela Lei no 12.651 , de 25 de maio de 2012 que dispõe sobre a proteção da vegetação nativa. Tal lei revogou o Código Florestal de 1965 - Lei № 4.771, de 15 de setembro de 1965 - e representa um novo marco florestal que prevê uma série de instrumentos que deverão auxiliar tanto governo quanto produtores rurais na gestão ambiental de propriedades e posses rurais, bem como no monitoramento e no combate ao desmatamento ilegal (CHIAVARI; LOPES, 2016).

Sumariamente, o novo Código Florestal mantém a mesma estrutura e conceitos fundamentais do antigo código, como as Áreas de Preservação Permanente (APPs) e a Reserva Legal, porém tiveram suas métricas significativamente alteradas e condicionadas a recortes fundiários. A nova lei também implicou em anistia das multas e sanções decorrentes dos desmatamentos ilegais realizados antes da promulgação da Lei de Crimes 
Ambientais - $n^{\circ}=6.514$, de 22 de julho de 2008 - e na isenção, em especial para os pequenos produtores - área de até 4 (quatro) módulos fiscais - de sua obrigatoriedade de recuperar áreas desmatadas. Ela também criou novos instrumentos e descentralizou para as Unidades Federativas sua gestão e monitoramento. A discussão entre parlamentares, ruralistas e ambientalistas que procedeu até a aprovação do novo Código Florestal se deu de forma acalorada, por vezes inócua, e sua implementação ainda é vista com muita preocupação (CHIAVARI; LOPES, 2016).

Apesar de todo o debate que circunda o desafio de cumprir as obrigações previstas no novo Código Florestal e do histórico sobre o descumprimento da lei anterior, o novo código conta com algumas novidades que, de certo modo, geram boas expectativas de implementação, pois visam estimular uma maior conformidade por meio de mecanismos de flexibilidade de forma a gerar maior incentivo à preservação e conservação dos ecossistemas.

Entre essas novidades encontra-se as Cotas de Reserva Ambiental (CRAs), as quais permitem a criação de mercados para a comercialização de ativos ambientais, que são áreas com vegetação nativa que já existem na propriedade ou estão em processo de recuperação e servem para compensar reserva legal de imóvel situado no mesmo bioma. Esse instrumento tem como objetivo a criação de um mercado em que os proprietários de terras dentro de um mesmo bioma possam negociar reservas excedentes entre si, ou seja, aquele proprietário que tiver déficit de reserva legal pode compensar negociando áreas de quem tem vegetação nativa acima das porcentagens exigidas pela lei (CHIAVARI; LOPES, 2016; MAY et al., 2015; MONZONI; VENDRAMINI, 2015).

Instrumento semelhante às cotas de reserva ambiental já existia no Código Florestal anterior e recebia o nome de Cotas de Reserva Florestal. No entanto, de acordo com May et al. (2015), sua implementação foi muito limitada devido ao fato de que as restrições de compensação por parte dos produtores teriam de ser na mesma bacia hidrográfica. As CRAs tem características que fazem dela um instrumento mais inovador em termos de proteção ambiental, pois, a partir do momento que permite uma maior flexibilização para o cumprimento das obrigatoriedades prescritas no novo Código Florestal, ela 
oferece possibilidades de suprir as deficiências e reduzir a dependência dos produtores aos instrumentos de comando controle na conservação e recuperação ambiental.

No entanto, sua implementação esbarra na escassez de recursos econômicos e humanos para a fiscalização contínua e efetiva por meio dos órgãos reguladores, o que pode requerer altos custos, especialmente, em países com uma grande extensão territorial. Tais fatores podem gerar um cenário de insegurança em relação ao instrumento dificultando a consolidação de sua efetiva aplicação bem como comprometendo seus resultados finais. Como apontado por Bernasconi (2013), embora existam dificuldades, tal instrumento se mostra importante principalmente por considerar melhor as heterogeneidades de aptidão agrícola e fragilidades ambientais, o que contribui diretamente para a redução dos custos de oportunidade para o produtor da conservação florestal dentro das propriedades ou posses.

Com o exposto, se houver flexibilidade na consecução dos objetivos de conservação das CRAs, poderia haver maior incentivo de conservação em terras com baixos custos de oportunidade agrícola, encorajando atores chaves desse processo, como os proprietários rurais e posseiros, a adotarem tal instrumento. Inspirado nesse potencial, o presente estudo tem por objetivo analisar tal instrumento sob os critérios de avaliação de política pública ambiental. Tal avaliação é essencial na fundamentação da escolha de política por parte do gestor e é capaz de identificar se o instrumento é de fato capaz de atingir o seu objetivo primordial.

\section{AS COTAS DE RESERVA AMBIENTAL NO NOVO CÓDIGO FLORESTAL}

Historicamente, o governo brasileiro tem o compromisso com a preservação florestal, compromisso esse instituído pelo Código Florestal de 1965. É também um fator histórico a dificuldade de se implementar alguns conceitos do mesmo, como o de Reserva Legal, cujos pontos mais críticos relacionam-se aos altos custos a ela associada e ao alto grau de restrição que ela impõe às propriedades rurais. A Reserva Legal $(R L)$ foi estabelecida pela Lei no 4.771, de 15 de setembro de 1965, juntamente com as Áreas de Preservação 
Permanente (APPs). Esses dois instrumentos constituem os principais marcos relacionados ao regramento jurídico disposto sobre a proteção da vegetação nativa no Brasil (CHIAVARI; LOPES, 2016; MAY et al., 2015).

Com o objetivo de preservar remanescentes da vegetação nativa e conservar a biodiversidade, a Reserva Legal (RL) é estabelecida como uma proporção fixa da área total do imóvel rural diferenciada de acordo com os principais biomas do país (Amazônia, Cerrado, Mata Atlântica, Caatinga e Pampa), na qual é obrigatório manter a cobertura da vegetação natural. $\mathrm{Na}$ área de $R L$ não é permitido manter nenhum tipo de atividade econômica tradicional, como pecuária, extração de madeira ou agricultura, admitindo-se apenas exploração mediante práticas de manejo sustentáveis. Já as APPs destinam-se à proteção da vegetação em áreas sensíveis, tais como áreas de matas ciliares, encostas íngremes e topos de morros onde o uso dos recursos florestais para fins produtivos dessas áreas é totalmente restrito e a supressão de vegetação só pode ser autorizada nas hipóteses previstas na lei (DE ALCANTRA, 2016; CHIAVARI; LOPES, 2016; MAY et al., 2015).

Com o Novo Código Florestal, aprovado pela Lei Federal oㅜ 12.651, de 25 de maio de 2012, a compensação de Reserva Legal ganha uma nova projeção, sendo encarada como peça chave para assegurar a regularização ambiental das propriedades rurais oferecendo aos proprietários uma alternativa de ganhos econômicos em áreas rurais já consolidadas em algum tipo de atividade produtiva e, simultaneamente, incrementando o valor de remanescentes florestais já existentes. Tal projeção é materializada em um novo instrumento previsto no Código Florestal de 2012, as Cotas de Reserva Ambiental (CRA), instituídas como um título nominativo que representa uma área com vegetação nativa - existente ou em processo de recuperação - que deverá servir para compensar reserva legal de imóvel rural situado no mesmo bioma (BRASIL, 2012, art.44). Tal instrumento tem como objetivo a criação de um mercado de compra e venda de CRA na qual quem tem um déficit de $\mathrm{RL}$ poderá compensar comprando títulos de quem tem vegetação nativa acima das porcentagens exigidas pela lei (CHIAVAR; LOPES, 2016). 
Para que a emissão do CRA seja feita é preciso que o proprietário esteja inscrito no CAR - Cadastro Ambiental Rural - que é um registro ambiental georreferenciado que tem por objetivo facilitar o monitoramento da regularidade ambiental da propriedade para qual se prevê uma aplicação mais rigorosa da lei. O CAR é um instrumento essencialmente declaratório, no entanto a inscrição no mesmo é obrigatória para todos os imóveis e posses rurais existentes no território nacional (MAY et al., 2015).

A CRA poderá ser emitida nas seguintes situações, como apontado pelo art. 44 da Lei 12.651/2012: I - sob regime de servidão ambiental; II correspondente à área de Reserva Legal instituída voluntariamente sobre a vegetação que exceder os percentuais exigidos no art. 12 desta Lei ${ }^{5}$; III protegida na forma de Reserva Particular do Patrimônio Natural - RPPN, nos termos do art. 21 da Lei no 9.985, de 18 de julho de 2000 e, desde que não coincida com a área de RL do imóvel; IV - existente em propriedade rural localizada no interior de Unidade de Conservação de domínio público que ainda não tenha sido desapropriada.

Ainda de acordo com essa mesma lei, art. 49, cabe fundamentalmente ao proprietário do imóvel rural em que se situa a área vinculada à CRA a responsabilidade plena pela manutenção das condições de conservação da vegetação nativa da área que deu origem ao título. Para o demandante da CRA, é importante destacar o impedimento do uso do mecanismo de compensação toda vez que este tiver finalidade de converter novas áreas florestadas para uso alternativo do solo, ficando, assim, impedido a supressão de vegetação em áreas com déficit em Reserva Legal (DE ALCANTRA, 2016).

Ainda que a CRA tenha sido instituída com a intenção de permitir a regularização da situação de déficit em $R L$ com compensação fora do imóvel

\footnotetext{
${ }^{5}$ Art. 12. Todo imóvel rural deve manter área com cobertura de vegetação nativa, a título de Reserva Legal, sem prejuízo da aplicação das normas sobre as Áreas de Preservação Permanente, observados os seguintes percentuais mínimos em relação à área do imóvel, excetuados os casos previstos no art. 68 desta Lei: I - localizado na Amazônia Legal:

a) $80 \%$ (oitenta por cento), no imóvel situado em área de florestas;

b) $35 \%$ (trinta e cinco por cento), no imóvel situado em área de cerrado;

c) $20 \%$ (vinte por cento), no imóvel situado em área de campos gerais;

II - localizado nas demais regiões do País: $20 \%$ (vinte por cento).
} 
rural, a Lei no $12.651 / 2012$ no parágrafo sexto do Art. 66 prevê alguns requisitos restringindo a localização da área de compensação: I - ser equivalentes em extensão à área da Reserva Legal a ser compensada; II - estar localizadas no mesmo bioma da área de Reserva Legal a ser compensada; III - se fora do Estado, estar localizadas em áreas identificadas como prioritárias pela União ou pelos Estados. Além disso, o parágrafo sétimo do referido artigo define que essas áreas deverão favorecer a recuperação de bacias hidrográficas excessivamente desmatadas, a criação de corredores ecológicos, a conservação de grandes áreas protegidas e a conservação ou recuperação de ecossistemas ou espécies ameaçadas.

Como apontado por Alcantra (2016), ainda há uma grande insegurança jurídica a respeito dos meios previstos para a operacionalização das CRAs. A esse fato soma-se a existência de questionamentos a respeito de um instrumento fundamental para a materialização das CRAs, que é o CAR, que dificulta a aplicação dos conceitos legais pelos órgãos ambientais trazendo um grau adicional de incerteza para a implementação efetiva desse instrumento de compensação.

Existem ainda outros aspectos relacionados diretamente ao regramento jurídico para que haja uma boa execução das CRAs, que são, de acordo com May et al. (2015), a existência de direitos de propriedade seguros para ambas as áreas de oferta e demanda do instrumento, além de um robusto monitoramento e efetiva aplicação da lei sob as áreas de conservação, bem como a existência de custos de transação razoavelmente baixos para o funcionamento do sistema de negociação.

\section{COTAS DE RESERVA AMBIENTAL COMO INSTRUMENTO DE GESTÃO DO MEIO AMBIENTE}

As CRAs, assim como outros instrumentos de compensação que podem ser realizados nos termos da Lei Federal o $12.651 / 2012^{6}$, são alternativas

\footnotetext{
${ }^{6}$ De acordo com o Código Florestal de 2012, a compensação de Reserva Legal pode ocorrer desde que não resulte na conversão de novas áreas para uso alternativo do solo. A compensação poderá ser realizada por meio de quatro mecanismos previstos pelo Código Florestal de 2012: $i$ ) a geração de CRA gerada em
} 
baseadas na flexibilização espacial de áreas para compensar a déficits em $R L$ das propriedades rurais e tem como aspecto importante o fato de reduzir os custos associados às ações de conservação a compensação. De acordo com Chomitz (2004), os mecanismos de compensação são vistos como uma importante forma de estimular a preservação ambiental de florestas privadas remanescentes no Brasil, pois se houver flexibilidade na consecução dos objetivos de conservação haverá maior incentivo na direção da conservação em terras com baixos custos de oportunidade agrícola, fornecendo, simultaneamente, incentivos adequados aos proprietários afetados, ou seja, aqueles com déficits de vegetação nativa em seu estabelecimento.

O mecanismo de compensação de $R L$ por meio da CRA insere-se na categoria de instrumentos econômicos de gestão ambiental, ainda pouco utilizado pela legislação ambiental brasileira (DE ALCANTRA, 2016). Os instrumentos econômicos buscam alcançar metas ambientais por meio de incentivos e desincentivos via sistema de preços, diferentemente dos instrumentos regulatórios ou de comando e controle, que são voltados para a regulamentação direta, acompanhada de fiscalização e sanção caso haja o nãocumprimento das normas e padrões estabelecidos pelo órgão regulador (NOGUEIRA; PEREIRA, 2000).

Como apontado por Banwart (2018), os instrumentos econômicos são capazes de afetar diretamente o cálculo de custos e benefícios dos agentes econômicos, influenciando suas decisões e, por extensão, produzindo melhorias na qualidade ambiental. Tais instrumentos procuram internalizar os custos ambientais nas atividades econômicas como forma de incentivar o agente responsável pelo dano ambiental a modificar o padrão de uso do recurso natural, o que se torna um diferencial relevante em relação aos instrumentos de comando e controle. Além disso, parte das discussões sobre política ambiental em nível

conformidade com as normas aplicáveis e em áreas de excedente florestal; ii) o arrendamento de outra área sob regime de servidão ambiental; iii) doação ao poder público de área localizada no interior de Unidade de Conservação de domínio público pendente de regularização fundiária; $i v$ ) o cadastramento de outra área equivalente e excedente à RL, em imóvel de mesma titularidade ou de terceiro, com vegetação nativa estabelecida, em regeneração ou recomposição desde que localizada no mesmo bioma (BRASIL, 2012,art.66, $\left.\$ 5^{\circ}\right)$ 
internacional é pautada na teoria econômica que tem por base o conceito de externalidades (MONOZONI; VENDRAMINI, 2015).

As CRAs guardam um paralelo interessante com os créditos de carbono e outros mecanismos de cap and trade, sendo um instrumento que deverá ser operado de forma contratual em bolsas de mercadoria de âmbito nacional ou em sistemas de registro e de liquidação financeira de ativos autorizados pelo Banco Central do Brasil (BRASIL, 2012, art. 47). Nesses mecanismos é o Estado que deverá determinar o nível ótimo de vegetação nativa a ser negociada no âmbito das CRAs, bem como o nível ótimo de poluição correspondente, por exemplo, aos créditos de carbono. Muito embora haja essa semelhança, como apontado por Milaré e Machado (2013), as CRAs não irão expressar em si uma verdadeira operação de crédito, mas sim representariam mercadorias ou bens que fundamentam sua existência. Além disso, mercados como os de créditos de carbono negociam o direito de poluir, ou impactar, diferentemente das CRAs que transacionam a obrigação de preservar (PORTO; SANTOS, 2017).

A lógica que rege a CRA como mecanismo de compensação de $R L$, deriva de custos de oportunidade da terra com diferentes rentabilidades e diferentes usos do solo, tornando menos oneroso conservar ou restaurar florestas em áreas com rendimento agrícola mais baixo enquanto mantém a agricultura em áreas de valor agrícola mais alto.

Além disso, permitir a compensação por meio dessa flexibilização pode potencialmente possibilitar uma produção agrícola menos fragmentada e mais eficiente, bem como a conservação de florestas a baixos custos em comparação aos mecanismos regulatórios, cuja exigência legal padrão de que cada propriedade tem que manter determinada cota de vegetação nativa, não levam em consideração as especificidades dessa mesma propriedade originando altos custos associados ao cumprimento da lei (MAY et al., 2015).

Ainda que as CRAs não representem efetivamente um ganho monetário líquido aos proprietários da terra, em conjunto, elas representam potencialmente uma oportunidade de reduzir custos associados à regularização para aqueles proprietários em situação de déficit, bem como incentivos positivos para aqueles que conservam além do exigido, produzindo ganhos de eficiência econômica ao 
mesmo tempo em que promove benefícios relevantes em termos ambientais. Como pode ser observado, tal instrumento tem, aparentemente, o propósito de conciliar conflitos entre interesses relacionados às atividades desenvolvidas nas propriedades rurais vis-à-vis interesses de preservação ambiental como um todo, ao mesmo tempo em que objetiva alcançar os objetivos legais de conservação prescritos pelo Código Florestal de 2012 (DA SILVA; RANIERE, 2014; MAY et al., 2015).

Diante desse propósito, é de interesse analisar os critérios pelos quais é possível julgar as CRAs como instrumento econômico de gestão ambiental de qualidade na consecução do seu objetivo, garantido resultados ambientalmente eficazes, economicamente eficientes e socialmente justos. Há certo consenso na literatura relacionada a economia ambiental sobre os critérios pelos quais avalia-se os instrumentos de gestão do meio ambiente, principalmente no que diz respeito aos seus aspectos políticos, econômicos e institucionais que pode fazer de tais instrumentos viáveis ou não no alcance do seu objetivo de proteção ambiental.

Nesse estudo será detalhado os critérios sugeridos por Perman et al. (2003) que parte de uma pressuposição geral sobre critérios de escolha de instrumentos de política pública. Tais critérios são: i) eficácia; ii) eficiência; iii) custos administrativos; iv) equidade; v) motivação ou incentivo ao esforço máximo; vi) aceitação política; vii) permanência; viii) interferências mínimas com decisões privadas. Para esses autores, o sucesso de um instrumento de política ambiental está intimamente relacionado a estes critérios de escolha que serão detalhados a seguir à luz dos aspectos relacionados às CRAs.

\subsection{EFICIÊNCIA E EFICÁCIA}

$\mathrm{Na}$ opinião de Perman et al. (2003), dentre os critérios utilizados para avaliar os instrumentos de política pública de proteção ambiental, o mais importante deles seria a eficiência também denominada como critério de custoeficiência. A eficiência relaciona-se a seleção de metas que equilibrem razoavelmente custos e benefícios para atingir objetivos ao mínimo custo, sendo ela claramente um dos atributos mais desejáveis de qualquer instrumento de 
política pública. Se um instrumento específico pode alcançar seu objetivo ao menor custo real do que qualquer outro significa que ele tem custo de oportunidade mínimo, um pré-requisito para alcançar uma alocação economicamente eficiente de recursos.

Já a eficácia é a capacidade do instrumento atingir o objetivo estabelecido (NOGUEIRA; PEREIRA, 2000). Se atingir o alvo fosse tudo que importava, a escolha do instrumento seria sem dúvidas relativamente mais simples, pois o melhor instrumento seria aquele que pudesse atingir seu objetivo ao maior grau de confiabilidade.

Em contraposição aos instrumentos de comando e controle, os instrumentos econômicos de gestão ambiental são significativamente mais eficazes e com e eficiência mais positiva, principalmente se os mercados onde atuarem também o forem. Em um contexto como esse, o instrumento irá alcançar seus resultados a um custo relativamente mais baixo para a sociedade, o contrário do que acontece com os instrumentos de controle direto que, à medida que a crise ambiental se torna mais grave, os custos para equacioná-la tendem a aumentar significativamente (NOGUEIRA; PEREIRA, 2000).

Em relação a CRA é importante ressaltar a consideração de Chomitz (2004) pelos mecanismos de compensação evidenciando o fato de esses representarem potencialmente uma solução economicamente mais eficiente para um objetivo global de conservação. Muito embora nesses termos as CRAs possam ser caracterizadas quase imediatamente como um instrumento eficiente de gestão do meio ambiente, deve-se lembrar de algumas restrições que podem elevar seus custos de implantação e execução tornando-a, em determinados contextos, um instrumento pouco eficiente.

Tais restrições foram apontadas por May et al. (2015) e Alcantara (2016), e referem-se a questões como o alto esforço administrativo e jurídico necessário para realizar as transferências de crédito necessárias na operacionalização desse mecanismo. Tal esforço pode vir a gerar altos custos de transação o que vem a reduzir a eficiência do instrumento. Outra questão que também tem efeitos sobre a elevação dos custos de transação diz respeito à complexidade institucional das regras para registro de terras disponíveis para a negociação, o 
que adicionaria múltiplas camadas de custos de transação sufocando facilmente tal instrumento. Essas características relacionadas diretamente ao regramento jurídico e administrativo das CRAs consequentemente geram perda de eficácia do instrumento, pois dificulta diretamente a consolidação de sua aplicação.

May et al. (2015) ainda aponta questões geográficas de influência sobre a perda de eficiência do instrumento. Ao mesmo que tempo em que no código florestal anterior o fato da compensação de $R L$ só poder ser realizada em região de mesma bacia hidrográfica no âmbito da negociação das cotas de reserva florestal ser considerado um fator muito restritivo para o funcionamento do instrumento, pela nova formulação no código de 2012, o fato da compensação poder ocorrer em região de mesmo bioma pode ser excessivamente amplo. $\mathrm{O}$ trade-off que se estabelece entre a compensação em um escopo mais restrito e outro mais amplo pode contrapor a otimização de serviços ecossistêmicos locais e redução de custos de monitoramento à perda de liberdade em termos de escolha de áreas com florestas elegíveis onde ocorrem os déficits de RL.

Segundo Young et al. (2017), essa questão afeta também o volume de transações e os preços praticados. Um sistema de compensação mais restrito pode resultar em um volume menor de transações com preços maiores. Já em um escopo mais amplo de negociações é possível que haja um maior volume de transações com preços mais baixos. Por outro lado, um sistema mais flexível tende a concentrar áreas de compensação em regiões do país onde o preço da terra é mais barato, enquanto um sistema mais restrito e rigoroso é capaz de gerar maior pulverização de áreas de florestas nativas entre as diferentes regiões brasileiras.

Assim, negociações mais restritas podem originar escassez em relação às áreas de florestas elegíveis o que, por consequência, aumenta os custos do instrumento ocasionando perdas em relação a sua eficiência, embora a compensação nesse caso irá ocorrer onde exista a demanda para determinado serviço ecossistêmico. Já as negociações em escopo mais amplo permite a redução de custos ao incluir na negociação os proprietários de terra em áreas cobertas com vegetação natural em regiões com baixa aptidão agrícola e baixos riscos de se tornarem sujeitas ao desmatamento ou outro tipo de degradação 
reduzindo os custos de regularização daquelas áreas onde há expansão agrícola gera uma maior pressão para conversão do uso do solo para atividade produtiva (BERNASCONI, 2013; MAY et al., 2015).

\subsection{CUSTOS ADMINISTRATIVOS}

O custo administrativo dos instrumentos de política ambiental refere-se à complexidade e os custos dos recursos necessários para administrar tal instrumento (OCDE, 1997; NOGUEIRA; PEREIRA, 2000). O instrumento com o menor custo administrativo será o preferido. Em geral, ambos os instrumentos de comando e controle e instrumentos econômicos tendem a ter elevados custos administrativos, tanto pelo estabelecimento de legislações, padrões e monitoramento do primeiro quanto pela exigência efetiva de monitoramento constante do segundo.

Como destaca Field (1997), a execução de leis exige energia e recursos como qualquer atividade. A execução das leis não ocorre de modo automático e é difícil ter as informações adequadas sobre o comportamento dos agentes quanto ao cumprimento e execução das leis. Estes custos administrativos constituem uma fração importante dos programas ambientais e, como em todo lugar, as instituições públicas enfrentam restrições orçamentárias. Dessa forma, os custos administrativos, mesmo não sendo tão elevados como os custos totais, são decisivos para o êxito dos programas ambientais e devem ser levados em consideração explicitamente no montante total dos custos sociais de políticas ambientais.

Em relação às CRAs, os custos administrativos são também um aspecto fundamental, pois, como já visto, eles podem incorrer em perdas de eficiência do instrumento. Os custos administrativos mais relevantes no âmbito das CRAs podem estar associados à sua fase de implantação que conta com várias etapas envolvendo diferentes órgãos e instituições nesse processo e muitas das vezes de diferentes estados, dado o escopo amplo em que deve se dar as negociações. 
Após a fase em que se celebra efetivamente o instrumento contratual de cessão dessas cotas é provável que os custos administrativos se reduzam uma vez que a operacionalização do instrumento passa a ser dada de forma automatizada em plataformas de negociações, como a Bolsa Verde do Rio de Janeiro (BVRio). A BVRio é uma organização sem fins lucrativos de assessoria para a negociação de ativos ambientais, que opera por meio de uma plataforma online permitindo que os agentes do mercado identifiquem parceiros adequados para as operações de compra e venda de CRA, proporcionando maior agilidade nas negociações. De acordo com os gestores da BVRio, o que o mercado exige para operar bem é um quadro regulatório adequado, com mínima burocracia o que reduz relativamente os custos administrativos da operacionalização do instrumento (MAY et al., 2015).

No entanto, até a fase em que o instrumento está em plena possibilidade de negociação entre ofertantes e demandantes de CRAs, as várias etapas previstas que envolvem, entre outros aspectos, a averbação da CRA na escritura dos imóveis (ofertante e demandante), a aprovação do Órgão Estadual de Meio Ambiente (OEMA), a inscrição no sistema do CAR (SICAR), entre outros elementos, adicionam complexidade ao processo, especialmente se envolverem estados diferentes.

Tal complexidade, aliada à insegurança em relação aos órgão que são responsáveis pela celeridade às demandas por inspeção, registro, monitoramento para que as CRAs sejam emitidas, transferidas e canceladas, aumentam não só os custos administrativos, como também os custo de transação e insegurança jurídica por parte do agente que poderá vir a demandar a CRA (MONZONI; VENDRAMINI, 2015).

\subsection{EQUIDADE}

De acordo com Nogueira e Pereira (2000), o critério de equidade envolve considerações éticas, sociais e políticas relacionadas à distribuição de custos e benefícios do instrumento. Como sugerido por Perman et al. (2003), é possível associar tal critério a seguinte questão: quais as implicações que a utilização de determinado instrumento tem sobre a distribuição da renda e da riqueza? 
A equidade é um critério importante para avaliar as políticas ambientais, de certa forma tem a ver também com a efetividade da política pública, dado que as políticas não podem ser apoiadas exclusivamente ao âmbito político, se é levado em consideração inequidades. Deve-se considerar quem arcará com os custos e quem receberá os benefícios. Entretanto, não é tarefa simples determinar os impactos distribucionais de qualquer política ambiental (FIELD, 1997).

É provável que a questão de equidade no âmbito das CRAs esteja atrelada à sua concepção no que diz respeito ao custo de oportunidade de uso do solo. $O$ fato de as florestas usadas para a compensação virem de onde a pressão para a conversão do uso do solo é baixa em relação às regiões de maior custo de oportunidade, que são aquelas em expansão agrícola, estabelece um critério, a princípio, equânime desse instrumento. E no que diz respeito às pequenas propriedades, que são aquelas com até quatro módulos fiscais, essas também podem emitir títulos de CRA, podendo desse modo, desempenhar um papel fundamental nesse mercado. Em geral, esses estabelecimentos apresentam um baixo custo de oportunidade de uso do solo e por isso terão um incentivo a mais para manter áreas de florestas em seus estabelecimentos tornando-se agentes de interesse em ofertar áreas elegíveis para realização de compensação por parte de outros proprietários que possuem déficit em RL.

É importante ressaltar que o Código Florestal de 2012 estabelece outros tratamentos diferenciados a pequenas propriedades rurais, como a anistia aos pequenos produtores das obrigatoriedades de recuperar áreas desmatadas, cuja conversão de uso do solo tivesse ocorrido antes da promulgação da Lei de Crimes Ambientais de 22 de julho de 2008, bem como a remissão de multas e sanções decorrentes de atividades ilegais ocorridas antes dessa mesma data. Até que ponto essas anistia interferem no caráter equânime das CRAs? Há de se observar que, de acordo com estimativas feitas por Soares-Filho (2013), das cerca de 5 milhões de fazendas brasileiras, 92\% têm área de até quatro módulos fiscais, embora estas representem apenas 30\% da área total.

Diante disso, tal anistia deve ser traduzida como um esforço de neutralizar dificuldades anteriores do cumprimento das obrigações do percentual padrão do 
código anterior e da falta de tecnologias ou insumos para a realização de restauração por parte dessas pequenas propriedades. Em situação de déficit de $\mathrm{RL}$ tais propriedades também poderão demandar CRAs, estimulando uma maior conformidade por meio da flexibilização da obrigatoriedade de manter determinado percentual de vegetação nativa em seu estabelecimento.

Outra vantagem relacionada ao critério de equidade das CRAs, concedida pelo Código Florestal de 2012 para imóveis com até quatro módulos fiscais, diz respeito ao fato de que os proprietários ou posseiros poderão emitir CRA sob a vegetação nativa que compuser a reserva legal, enquanto, para os demais imóveis com mais de quatro módulos fiscais fica a obrigatoriedade de emitir CRAs somente sob a vegetação nativa que exceder a reserva legal.

Ademais, outros procedimentos mais simplificados relacionados aos aspectos regulatórios pra emissão de CRAs - como por exemplo a obrigatoriedade do poder público em prestar assessoria técnica e jurídica, além de captar as respectivas coordenadas geográficas para a inscrição no Cadastro Ambiental Rural (CAR) - e outras atividades de compensação por parte de pequenos proprietários estão estabelecidos no Código Florestal de 2012 e são discutidas amplamente nos trabalhos de Chiavari e Lopes (2016) e Alcantara (2016).

No entanto, existe um entrave relevante à participação dos pequenos proprietários no mercado de CRA. Estimativas de Soares-Filho (2014) apontam que apenas $17 \%$ dessas pequenas propriedades possuem títulos plenamente registrados e suprem as exigências de comprovação de propriedade. Isto implica em um grande desafio para assegurar a participação das pequenas propriedades no mercado de CRA (além daquele associado aos custos de transação), considerando a exigência de que os emitentes de CRA devem ter direitos de propriedade regularizados na forma de títulos de terras registrados.

Mesmo com obrigações menos rígidas e etapas mais simples, a equidade do instrumento em relação aos seus potenciais benefícios para os pequenos produtores pode ser comprometida por questões genuínas de direitos de propriedade, aspecto tão fundamental para o pleno funcionamento de qualquer instrumento de política de gestão ambiental. 


\subsection{MOTIVAÇÃO OU INCENTIVO AO ESFORÇO MÁXIMO}

Motivação ou incentivo ao esforço máximo ou, na classificação de Perman et al. (2003), eficiência dinâmica, refere-se à capacidade do instrumento em gerar incentivos contínuos para o aprimoramento de produtos ou processos de produção visando a redução da poluição, por exemplo. Por esse critério, o instrumento deve gerar uma motivação contínua de redução dos impactos nocivos sobre o meio ambiente, levando o agente que degrada ou polui a ultrapassar a meta ambiental estabelecida em uma busca permanente de melhorias (NOGUEIRA; PEREIRA, 2000). Ou seja, é o critério que dita a capacidade de o instrumento de ir além do que foi estabelecido pela autoridade pública.

Os instrumentos econômicos vis-à-vis os instrumentos de comando e controle são muito mais vantajosos por esse critério. Por exemplo, no caso da necessidade de uma redução da poluição, por meio do uso de instrumentos econômicos os agentes serão mais motivados a minimizar os danos ambientais, uma vez que haverá um incentivo financeiro para que eles continuem a reduzir sua poluição, praticando de forma permanente inovações e/ou descobertas de formas menos onerosas de redução de poluição. Já os instrumentos de comando e controle não fornecem tal incentivo, a não ser o de atender os limites impostos pela legislação e pelos padrões, ou seja, a falta de contrapartida à redução da poluição ocasiona uma inércia por parte do poluidor, não havendo incentivo ao desenvolvimento e a adoção de novas técnicas ambientais (NOGUEIRA; PEREIRA, 2000).

Do ponto de vista da CRA, uma vez que as modificações de atitudes em relação ao meio ambiente forem atingidas, é de se esperar que os indivíduos sejam permanentemente motivados a manter suas atitudes em relação à preservação ambiental. Uma vez que o proprietário rural é obrigado a cumprir a porcentagem de reserva legal prevista em lei para sua propriedade, quando ele exceder esta obrigação, a lei permite a venda destas cotas a outros produtores que não cumpriram a legislação (DE ALCANTARA, 2016). 
A atividade é voluntária no que tange ao excedente. Deste modo, as duas partes se beneficiam sem abrirem mão de áreas produtivas e adequando-se à lei. Desse modo, a maior motivação pode estar associada à flexibilização provável para regularizar os déficits de reserva legal do estabelecimento, enquanto também fornece incentivos positivos para aqueles que conservam além do que é exigido por lei, mesmo que as CRAs não tragam efetivamente um ganho monetário líquido para os agentes envolvidos.

Mais uma vez, elementos que interferem na perda de eficiência do instrumento aqui estudado, também tem efeitos sobre a perda de motivação por parte do agente degradador. Elevados custos de transação, por exemplo, podem reduzir o incentivo de o agente entrar no mercado de CRAs, diminuindo as possibilidades de compensação de reserva legal por meio desse instrumento.

Outro ponto que gera perda em termos de motivação relaciona-se ao fato de que pode haver um contexto em que o valor das CRAs não será suficiente para cobrir os custos de oportunidade da produção agrícola, embora possa compensar em alguns casos como na regeneração natural em pastagens marginais de baixa produtividade. Assim, a venda de CRAs de áreas de oferta pode vir a atuar mais como um prêmio de consolação para aqueles que preservaram mais do que o exigido por lei, bem como para os pequenos agricultores que derrubaram todas as suas florestas, o que pode resultar em um baixo incentivo à adesão do instrumento por parte daqueles que tem alto custo de oportunidade de uso do solo e precisam regularizar seus déficits em RL (MAY et al., 2015).

\subsection{ACEITAÇÃO POLÍTICA}

O critério aceitação política aborda a capacidade de receptividade da política diante aos parlamentares e representantes da sociedade (BAULMOL;OATES, 1979). Nas palavras de Castro e Nadai (2012), aceitação política é o nível de aprovação dos instrumentos pelos distintos seguimentos da sociedade. Por conseguinte, um instrumento perfeito tecnicamente será inócuo se ele for rejeitado politicamente. A aceitação política está então relacionada à liberdade de escolha, sendo mais facilmente aceitos aqueles instrumentos que 
permitem mais opções de equacionamento do problema para o indivíduo ou a empresa. Ela também pode depender, por exemplo, de características históricas específicas da comunidade que o instrumento será implantado.

Em alguns casos é mais provável que instrumentos econômicos orientados para a gestão de meio ambiente tenham mais resistência em serem aceitos, como aqueles baseados em taxações e impostos. Todavia, ferramentas econômicas do tipo cap and trade, tem sido usada com sucesso em controle de poluição e gestão de recursos em vários países. Tal ferramenta estabelece direitos de propriedade, por exemplo, sobre o uso de um determinado recurso, e tem se mostrado uma opção muito flexível para que os agentes poluidores/degradadores cumpram com suas metas de redução de poluição atmosférica ou de exploração de determinados recursos naturais, como por exemplo, o estabelecimento de licenças para uso da água (NETTO; SOARES; NOGUEIRA, 2004).

Por esse aspecto, tanto pelo lado do setor produtivo quanto pelo lado do estado, tais instrumentos têm bastante aceitação, tanto pela descentralização de monitoramento e condução operacional do instrumento por parte do estado como também devido ao fato de permitir que os agentes do setor produtivo possam flexibilizar suas licenças de acordo com suas necessidades produtivas.

Pelo lado do setor produtivo, que são os proprietários dos estabelecimentos rurais, o processo de regularização ambiental por meio desse instrumento de compensação pode ter uma boa aceitação em vista da possibilidade de o produtor regularizar seus déficts de $\mathrm{RL}$ em outras regiões onde há excedente de vegetação nativa, que não em seu estabelecimento. Nas palavras de Chiavari e Lopes (2016), todo o processo de regularização ambiental dos imóveis rurais depende fundamentalmente da vontade e da iniciativa dos proprietários rurais, destinatários finais desse novo regramento do Código Florestal de 2012. Eles precisam entender objetivamente as regras, as etapas e os incentivos presentes no novo código para que ele seja efetivamente implementado.

Pelo lado do Estado, há de se levar em consideração o grande esforço do novo Código Florestal em regularizar a situação ambiental das propriedades 
rurais e por deveria ser de fundamental interesse das autoridades políticas. No entanto, em um trabalho recente de Carvalho, Lehfeld e Barbosa (2019), mostra que a avaliação técnico-jurídica do poder público na pessoa do Supremo Tribunal Federal (STF) tornou a regulamentação e a aplicação deste instrumento mais dificultada a partir dos entendimentos de que as CRAs apresentariam direcionamentos do agrobussines entre outros questionamentos levantados por meio de ações dirigidas ao STF. Isso mostra que, em sua atual normatização, as CRAs ainda necessitam de maturação técnica, jurídica e política para que seja efetivamente usufruída como uma estratégia de preservação e recuperação ambiental.

\subsection{PERMANÊNCIA}

Castro e Nadai (2012) definem permanência como a capacidade da política em provocar alterações permanentes no comportamento dos agentes econômicos, de tal forma que a retirada dos estímulos não provoque um retrocesso ao antigo comportamento. Assim, o aspecto primordial desse critério com relação às CRAs pode estar relacionado ao desafio acerca da viabilidade das CRAs em dois cenários fundamentais: I) no cenário apenas de CRAs como objeto de compensação de área de $R L$, cujo êxito desse objetivo estará associado a sua eficiência em atender a necessidade de regularização do déficit em RL do imóvel rural, e; ii) CRAs como objeto de interesse de investidores, como valores mobiliários, indo além, portanto, da compensação ambiental. Ou seja, a viabilidade econômica do potencial mercado de CRAs é também fundamental para a permanência do instrumento. Enquanto ativo financeiro, ela deve atrair os investidores com alguma expectativa de ganho, ao contrário de uma compra para consumo (MONZONI; VENDRAMINI, 2015).

De acordo com estimativas do Laboratório de Gestão de Serviços Ambientais e o Centro de Sensoriamento Remoto da UFMG, o mercado de CRAs, na maneira como está previsto no código florestal de 2012, mostra-se com grande potencial de ser implantado. De acordo com esse estudo, haveria uma superoferta de CRAs, sendo a oferta total provável de CRAs no Brasil de 103,1 milhões de hectares para uma demanda provável de 4,6 milhões de 
hectares. Ou seja, no agregado do País, a oferta seria 22 vezes maior que a demanda, embora o saldo entre oferta e demanda possa variar entre os estados e os biomas (RAJÃO; SOARES-FILHO; SANTIAGO, 2015; GASPARINETTI; VILELA, 2018)

Ademais, fatores que influenciam o preço das CRAs, também afetam o comportamento do mercado em que elas serão negociadas. Segundo Gasparinetti e Vilela (2018), um dos resultados do excesso de oferta de CRAs seria um preço de equilíbrio da mesma muito baixo, sendo, na pior das hipóteses, igual a zero a depender da situação entre ofertantes e demandantes de determinadas regiões. Ainda nesse sentido, o custo de oportunidade da terra e valor de mercado da terra, custos incorridos pelo ofertante de CRA para manter protegida a área excedente de $\mathrm{RL}$ que deu origem ao título, os chamados "custos de cercamento", o horizonte temporal de vigência do contrato, entre outros elementos, podem impactar diretamente nos estímulos que levam a permanência ou não do instrumento (MONZONI; VENDRAMINI, 2015).

\subsection{INTERFERÊNCIA MÍNIMA COM DECISÕES PRIVADAS}

O último critério de escolha de políticas públicas é a interferência mínima com decisões privadas. Este critério é uma propriedade da política de definir exatamente o que deve ser feito ou prover opções coerentes com a proteção ambiental para que possam ser feitas escolhas. Agentes preferem aqueles instrumentos que modifiquem o menos possível o seu modo usual de tomar decisões. Vale ainda destacar que por esse critério é privilegiada a busca da solução do problema ambiental pelos próprios agentes sociais envolvidos, motivando-os para a escolha daquelas que melhor se adapte as características de sua atividade (NOGUEIRA; PEREIRA, 2000; CASTRO; NADAI, 2012).

Ao contrário do que acontece com os instrumentos de comando e controle para a gestão do meio ambiente, os instrumentos econômicos tendem a exercer maior incentivo aos agentes envolvidos para que esses encontrem a melhor maneira de reduzir suas emissões ou degradação sem a necessidade de ter uma autoridade pública determinando como se deveria lidar com essa tarefa. No caso dos instrumentos de comando e controle, a interferência pública pode ser tão 
significativa que, em determinados casos, pode chegar à necessidade de fechamento de unidades produtivas por desobediência a padrões $e$ regulamentos estabelecidos pelo órgão regulador (NOGUEIRA; PEREIRA, 2000).

No caso das CRAs, uma vez estabelecido o regramento do Código Florestal de 2012 e superadas outras dificuldades de implantação do instrumento, , é possível que, após o instrumento implantado, haja interferência reduzida nas decisões dos agentes pelo setor público e isso se deve ao fato de o instrumento ser caracterizado pelo incentivo, e não pela coerção, e também pelo fato de as cotas serem negociadas em plataforma de negociações de ativos, ambiente em que há pouca interferência do estado (DE ALCANTARA, 2016).

Além disso, na forma como esse instrumento de compensação foi delineado, com uma lógica de tornar menos oneroso e mais flexível a regularização dos déficits em $R L$ dos estabelecimentos rurais, atende tanto aos interesses daqueles com atividade produtivas em regiões de valor agrícola mais alto e, ao mesmo tempo, permite conservar ou restaurar florestas nativas em regiões onde o rendimento agrícola é mais baixo, tornando menos necessário a intervenção por coerção de órgão reguladores para que os imóveis rurais cumpram com o que está estabelecido no Código Florestal de 2012 (MONZONI; VENDRAMINI, 2015).

\section{COMENTÁRIOS CONCLUSIVOS}

O presente estudo objetivou avaliar o instrumento das Cotas de Reserva Ambiental segundo os critérios de avaliação de política pública ambiental. Tais critérios são a eficiência, a eficácia, os custos administrativos, a equidade, a motivação ou incentivo ao esforço máximo, a aceitação política, a permanência e a interferência mínima com as decisões privadas. A literatura que trata sobre as CRAs como instrumento de compensação ambiental mostra que, em tese, esse seria um mecanismo potencialmente capaz de resolver o trade-off entre crescimento e conservação em propriedades privadas no Brasil.

No entanto, a partir da análise das características de tal instrumento, à luz dos critérios de avaliação, observou-se que ainda há vários elementos que 
impõem alguma dificuldade à implantação das CRAs impedindo o seu uso efetivo. No âmbito dos critérios de eficiência e eficácia, o estudo mostrou que restrições relacionadas aos aspectos jurídicos, podem elevar seus custos de implantação e execução tornando as CRAs um instrumento pouco eficiente e, pouco eficaz, devido às dificuldades de consolidação de sua aplicação.

Em relação aos custos administrativos, os custos associados a fase de implantação das CRAs parecem ser os mais relevantes, pois envolvem várias etapas, órgãos e instituições. É esperado que após a fase de implantação, tais custos sejam reduzidos, uma vez que a operacionalização do instrumento tende a acontecer de forma automatizada.

Quanto ao critério de equidade das CRAs, observou-se que esse deve ser o principal motivador para o pleno funcionamento do mecanismo de compensação ambiental, uma vez que as florestas usadas para compensação deverão vir de onde a pressão para conservação do uso do solo é mais baixa em relação as regiões de maior custo de oportunidade. A limitação, porém, são as questões de direitos de propriedade, que deixaria de fora pequenos produtores em situação de déficit de reserva legal, sem que esses pudessem usufruir dos potenciais benefícios de flexibilização.

A motivação ou incentivo ao esforço máximo no âmbito das CRAs deve ser alavancada a partir do momento em que o instrumento estiver em pleno funcionamento. A partir desse ponto, a atividade de negociações entre demandantes e ofertantes de CRAs, deverá ocorrer de forma voluntária. Esse aspecto ditaria a capacidade das CRAs ir além do que foi estabelecido pela autoridade pública.

Quanto ao critério de aceitação política, a literatura mostrou que instrumentos do tipo das CRAs costumam ter boa aceitação tanto do lado do setor produtivo, por permitir que os agentes possam flexibilizar suas licenças de acordo com suas necessidades produtivas, quanto do lado do estado, por descentralização o monitoramento e a condução operacional do instrumento. No entanto, ainda há muita insegurança técnica, política e jurídica em torno do funcionamento das CRAs, seja na ótica dos agentes ou da sociedade. 
O critério de permanência no âmbito das CRAs mostrou-se viável se ela for eficiente no seu objetivo de regular déficit em reserva legal, bem como se ela atrair interesse de investidores, indo além, da compensação ambiental. Nesses casos, o instrumento será capaz de provocar alterações permanentes no comportamento dos agentes econômicos. Por fim, para o critério de interferência mínima com decisões privadas, é possível que haja interferência reduzida nas decisões dos agentes privados pelo setor público, pela forma de delineamento do funcionamento das CRAs, o que não se verifica quando o instrumento de compensação tem bases mais coercitivas.

Note-se que todos critérios só serão atendidos no caso das CRAs estarem em pleno funcionamento, pois envolvem grande complexidade relacionada às diversas etapas que vão da sua concepção até a adesão pelas partes interessadas. Tais etapas ainda não foram devidamente regulamentadas pelos estados e ainda carecem de atenção em aspectos fundamentais, como os jurídicos, além da formalização e da possibilidade de ampla negociação, uma vez que a compensação pode ocorrer entre estados diferentes dado o escopo geográfico da negociação estar restrita a área de mesmo bioma.

Vislumbra-se assim, a necessidade de superar tais aspectos e envolver a classe rural, juntamente com o estado, conferindo clareza, incentivando e prestando a assessoria técnica necessária, para que tal mecanismo atinja os legítimos destinatários finais das normas regulamentadas pelo Código Florestal de 2012.

\section{REFERÊNCIAS BIBLIOGRÁFICAS}

BAUMOL, W.; OATES, W. E. Economics, Environmental Policy, and the Quality of Life. New Jersey: Prentice-Hall, 1979.

BERNASCONI, P. Custo-efetividade ecológica da compensação de reserva legal entre propriedades do estado de São Paulo. 2013. 113 f.. Dissertação (Mestrado em Desenvolvimento Econômico). Instituto de Economia. Universidade Estadual de Campinas, 2013.

BANWART,T O potencial da compensação de reserva Legal no município de Querência/M. 2018. 89 f.. Dissertação (Mestrado em Desenvolvimento Econômico). Instituto de Economia. Universidade Estadual de Campinas, 2018.

BRASIL. Presidência da República. Decreto Federal oㅜ 6.514, de 22 de julho de 2008. Dispõe sobre infrações e sanções administrativas ao meio ambiente, 
estabelece o processo administrativo federal para a apuração destas infrações, e dá outras providências. Diário Oficial da União, Brasília, 23 de julho, 2008.

BRASIL. Presidência da República. Lei Federal № 12.651, de 25 de maio de 2012. Dispõe sobre a proteção da vegetação nativa; altera as Leis $n^{\circ} 6.938$, de 31 de agosto de 1981, 9.393, de 19 de dezembro de 1996, e 11.428, de 22 de dezembro de 2006; revoga as Leis no 4.771, de 15 de setembro de 1965, e 7.754, de 14 de abril de 1989, e a Medida Provisória oㅡ 2.166-67, de 24 de agosto de 2001; e dá outras providências. Diário Oficial da União, Brasília, 25 de maio de 2012.

CASTRO, B. J.; NADAI, B. M. O instrumento de política ambiental "educação ambiental" à luz dos critérios de escolha de políticas públicas: estudo comparativo nos trabalhos de sodré e aciolly. Anais do Simpósio Nacional Espaço, Economia e Políticas Públicas, v. 2, n. 1, p. 182-197, 2014.

CARVALHO, D. W.; LEHFELD, L. S.; BARBOSA, K. S. A cota de reserva ambiental no Supremo Tribunal Federal: reflexões sobre o instituto após a declaração de constitucionalidade. Direito e Desenvolvimento, v. 10, n. 2, p. 179-200, 2019.

CHIAVARI, J.; LOPES, C. L. Os Caminhos para a Regularização Ambiental: Decifrando o Novo Código Florestal. In: Mudanças no código florestal brasileiro: desafios para a implementação da nova lei. Org.: SILVA, A, P. M.; MARQUES, H. R.; SAMBUICHI, R. H. R. 359 p. Rio de Janeiro: IPEA, 2016.

COSTA, M. M. Financiamento para a Restauração Ecológica no Brasil. In: Mudanças no código florestal brasileiro: desafios para a implementação da nova lei. Org.: SILVA, A, P. M.; MARQUES, H. R.; SAMBUICHI, R. H. R. 359 p. Rio de Janeiro: IPEA, 2016.

DA SILVA, J. S.; RANIERI, V. E. L. The Legal Reserve Areas Compensation Mechanism and its Economic and Environmental Implications. Associação Nacional de Pós-Graduação e Pesquisa em Ambiente e Sociedade. Ambiente \& Sociedade, v. 17, n. 1, 2014.

DE ALCANTARA, M. L. O Cadastro Ambiental Rural e as Cotas de Reserva Ambiental no Novo Código Florestal: Uma Análise de Aspectos Legais Essenciais para a sua Implementação. In: Mudanças no código florestal brasileiro: desafios para a implementação da nova lei. Org.: SILVA, A, P. M.; MARQUES, H. R.; SAMBUICHI, R. H. R. 359 p. Rio de Janeiro: IPEA, 2016.

DE ALMEIDA, L. T. Política ambiental: uma análise econômica. Papirus, 1998.

FIELD, B. Economia Ambiental: Uma Introducion. Santa Fé de Bogotá, McGraw-Hill, 1997.

GOTTLE, A.; SÈNE, E-H. Forest functions related to protection and environmental conservation. Unasylva (English ed.), v. 48, n. 190/191, p. 3037, 1997.

GASPARINETTI, P.; VILELA, T.. Implementando Mercados de Cotas de Reserva Ambiental (CRA) nos Estados Brasileiros: Desafios e Oportunidades para as 
Regulamentações Estaduais. Documento de Discussão. Conservação Estratégica, 2018.

GUEDES, F. B.; SEEHUSEN, S. E. Pagamentos por serviços ambientais na Mata Atlântica: lições aprendidas e desafios. Brasília: MMA, p. 12, 2011.

HANLEY, N.; SHOGREN, J. F.; WHITE, B. Environmental economics: in theory and practice. 2 ed. New York: Palgrave Macmillan, 2011.

MAY, P. H., BERNASCONI, P., WUNDER, S.; LUBOWSKI, R. Cotas de reserva ambiental no novo código florestal brasileiro: Uma avaliação ex-ante. vol. 146. Centro de Pesquisa Florestal Internacional, CIFOR, 2015.

MILARÉ, E.; MACHADO, P. A. Novo código florestal comentado: comentário à Lei oㅜ 12.651, de 25 de maio de 2012, à Lei o 12.727, de 17 de outubro de 2012 e ao Decreto no 7830 , de 17 de outubro de 2012. Revista dos Tribunais, $2^{\text {a }}$ ed. São Paulo 2013.

MONZONI, M.; VENDRAMINI, A. Cotas de Reserva Ambiental (CRA). Centro de Estudos em Sustentabilidade da Fundação Getúlio Vargas (GVces / FGVEAESP). Federação Brasileira de Bancos. Febraban, 2015.

NETTO, O. M. C.; SOARES, P. R. J.; NOGUEIRA, J. M. Tradable permits and water market: simulation and evaluation under small scale agricultural production conditions. (2004).

NOGUEIRA, J. M.; PEREIRA, R. R. Critérios e análise econômicos na escolha de Políticas Ambientais. Brasília: ECO-NEPAMA, 2000.

OCDE. Evaluating economic instruments for environmental policy. Organisation for Economic Co-operation and Development, 1997.

PERMAN, R.; MA, Y.; McGILVRAY, J.; COMMON, M. Natural resource and environmental economics. 3 Ed. Pearson Education, 2003.

PORTO, A. M.; DOS SANTOS, L. M. Cotas da Reserva Ambiental: Uma Interpretação da Análise Econômica do Direito. REI-REVISTA ESTUDOS INSTITUCIONAIS, v. 3, n. 2, p. 922-948, 2017.

RAJÃO, R.; SOARES-FILHO, B. S.; SANTIAGO, L. Estudo de viabilidade econômica do potencial mercado de Cotas de Reserva Ambiental (CRA) no Brasil. Federal University of Minas Gerais, Belo Horizonte, Brazil, p. 1-70, 2015.

SOARES-FILHO, B. S. Impacto da revisão do Código Florestal: como viabilizar o grande desafio adiante?. Secretaria de Assuntos Estratégicos da Presidência. 28p. 2013.

STERNER, T.; CORIA, J. Policy Instruments for Environmental and Natural Resource Management. NewYork e London: RFF Press, Resource for the Future, Second Edition, 2012, 638p.

YOUNG, C. E. F.; MENDES, M. P.; DA COSTA, L. DE A.; ALVARENGA JUNIOR, $M$. Custos e benefícios da implementação de um mercado de cotas de reserva ambiental (CRA) no Brasil. XII Encontro Nacional da Sociedade Brasileira de Economia Ecológica, v. 21, 2017. 